\title{
Relationship of vascular pathology, demographic and radio-anatomical features in aortic dissections detected by multidetector CT
}

\author{
Yusuf Secgin $^{1}$, Serkan Oner ${ }^{2 *}$, Zulal Oner ${ }^{3}$ \\ ${ }^{1}$ Department of Anatomy, Faculty of Medicine, Karabük University, Karabük, Turkey \\ ${ }^{2}$ Department of Radiology, Faculty of Medicine, Izmir Bakırçay University, Izmir, Turkey \\ ${ }^{3}$ Department of Anatomy, Faculty of Medicine, Izmir Bakırçay University, Izmir, Turkey
}

Received: 2021-09-29.

Accepted: 2021-11-03

This work is licensed under a

Creative Commons Attribution 4.0 International License

J Clin Med Kaz 2021; 18(6):40-44

Corresponding author:

Serkan Oner

E-mail: serkan.oner@bakircay.edu.tr ORCID: 0000-0002-7802-880X

\begin{abstract}
Aim: Aortic dissection is a cardiovascular disease with low incidence but high mortality. The aim of our study is to evaluate the demographic, vascular pathologic and radio-anatomic features of aortic dissection and find out the relationship of these with aortic dissection.

Material and methods: One female and 12 male patients admitted to the hospital with severe chest pain and diagnosed with aortic dissection by Computed Tomography were included in this study. Patients were divided into three groups according to the De Bakey classification. Type I: starting from the ascending aorta and ending in the thoracic aorta, Type II: starting from the ascending aorta and ending in the brachiocephalic artery, Type III: starting from the subclavian artery and ending at the level of the diaphragm and abdomen.

Results: The highest aortic dissection incidence was found in group Type III with $54 \%$. The ages of patients with aortic dissection were $56.67 \pm 12.50,61.00 \pm 11.53$ and $52.00 \pm 12.26$, respectively according to the groups. According to the Pearson Correlation test, significant correlations were found between ascending aorta and age and aortic arch, between cardiothoracic ratio and heart width, and between thoracic width and thoracic aorta $(p \leq 0.05)$. One Way Anova test was used for the analysis between dissection groups and significant correlation was found between Type II and Type III groups of ascending aorta parameter $(p \leq 0.05)$. In addition, it was found that $54 \%$ of the patients had mild atherosclerosis and $46 \%$ had lumen.

Conclusion: A significant relationship was found between aortic dissection and radio-anatomic parameters, demographic and vascular pathologic features.
\end{abstract}

Key words: aortic dissection, computed tomography, De Bakey classification

\begin{abstract}
Introduction
Aortic dissection is a vascular pathology that results in the rupture of the intima or adventitia layer of the aorta or the separation of these layers due to bleeding [1, 2]. Although the incidence of aortic dissection is low, it is a fatal disease with a mortality rate of $1-2 \%$ per hour in untreated patients in the acute period. Therefore, correct diagnosis is very important in terms of the prognosis of the disease. It should be diagnosed carefully since its symptoms are very similar to pathologies such as pulmonary embolism and acute myocardial infarct. Its symptoms include chest pain, hypotension and syncope $[3,4]$. According to studies conducted, aortic dissection is more frequent in male and old individuals with
\end{abstract}

chronic disease (arterial hypertension, dyslipidemia, atherosclerosis, aortic aneurysm, etc.) when compared with female and young individuals. However, it has also been reported in high rates in young individuals with Loeys Dietz syndrome [1-3, 5].

According to the literature, there are two common methods to classify aortic dissection. The first of these is Stanford classification, while the second one is De Bakey classification $[1,4,6]$. Stanford classification is a more limited classification than De Bakey classification [3, 4, 6]. Stanford groups aortic dissections in two types, type A dissections are seen in ascending aorta, while type B dissections are seen in the distal of subclavian artery [3]. According to De Bakey, dissections are grouped 
in three types. Type I starts from ascending aorta and ends at thoracic aorta. Type II starts from ascending aorta and ends at brachiocephalic artery. Type III starts from subclavian artery and ends on diaphragm (IIIa) or in abdomen (IIIb) [3, 6-8]. In addition, depending on the bleeding between the aortic layers, the layers may separate from each other and a lumen structure may occur. The lumen structure is also grouped in two as true lumen and false lumen. If the lumen in the dissected part of the aorta continues in the undissected part, this is called true lumen, if it does not, it is called false lumen [9, 10].

Magnetic Resonance Imaging (MRI), Contrast Computed Tomography (CT), Chest X-ray and Transesophageal Echocardiography (TEE), Ultrasonography (US) are used for the diagnosis and typing of aortic dissections $[1,3,5]$. CT is a cheap, accessible method that does not require specialized personnel, with high sensitivity and specificity, and three-dimensional imaging [1, 3]. Early treatment of aortic dissections is very important and there are different treatment methods such as medical treatment, open thoracic surgery, thoracic endovascular aorta repair (TEVAR) treatment $[3,5-8,11]$.

The aim of our study is to examine aortic dissections according to the most detailed De Bakey classification in the literature. Thus, demographic, pathological and radioanatomical changes of aortic dissections detected on CT images were examined.

\section{Material and methods Study Population}

The study was initiated with the 2021/616 numbered decision of Non-interventional Clinical Researches Ethics Committee. The patients who had thoracoabdominal CT angiography between 2015 and 2021 were scanned in Karabük University Training and Research Hospital Radiology archive. A total of 13 patients $(12 \mathrm{M}, 1 \mathrm{~F})$ with aortic dissection were found. The patients had presented with chest pain and hypotension symptoms.

\section{MDCT Scanning Protocol and Image Analysis}

All CT scans were performed by using a 16-row Multidetector CT scanner (Aquilion 16; Toshiba Medical Systems, Otawara, Japan). Scanning parameters were tube voltage: $120 \mathrm{kV}$, gantry rotation: $0.75 \mathrm{~s}$, pitch: $1.0 \mathrm{~mm}$ and section thickness: $1 \mathrm{~mm}$.

The images in Digital Imaging and Communications in Medicine (DICOM) format were transferred to personal workstation Horos Medical Image Viewer (Version 3.0, USA) program. All images were examined in axial, coronal and sagittal planes by a radiologist with at least 10 years of experience in the field and aortic dissection types, aortic lumen and atherosclerosis presence (mild-severe) were noted (Figure 1). The patients were grouped in three according to De Bakey classification. True and false lumen were distinguished radiologically and the veins emerging from the false lumen were determined (Figure 2). The following radio-anatomic measurements were made for all patients by using the measurement tool in the program:

- Ascending aorta diameter

- Aortic arch diameter

- Thoracic aorta diameter

- Abdominal aorta diameter

- Heart width

- Thoracic width

- Cardiothoracic ratio
Figure 1 - Dissection types according to De Bakey classification (a: Type I, b: Type II, c: Type III).

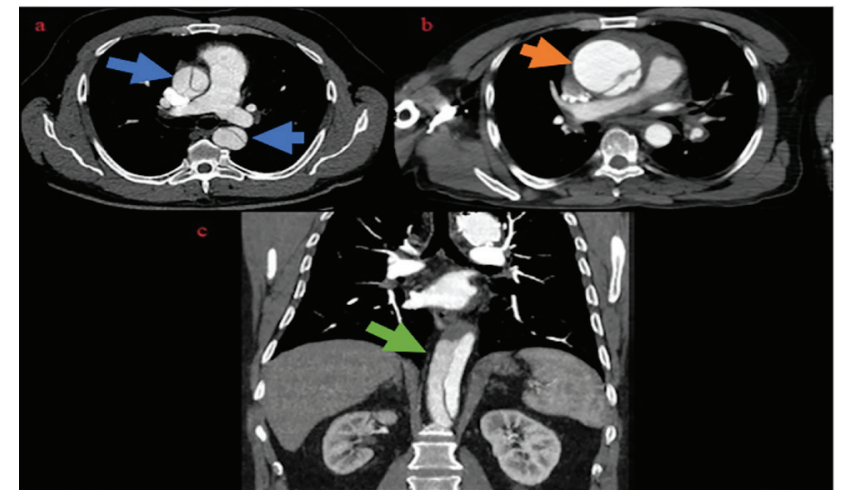

Figure 2 - Lumen formation demonstration (1: False lumen at right renal artery, 2: Both true and false lumen at right common iliac artery, 3: Both true and false lumen at brachiocephalic artery, right common carotid artery and left subclavian artery)

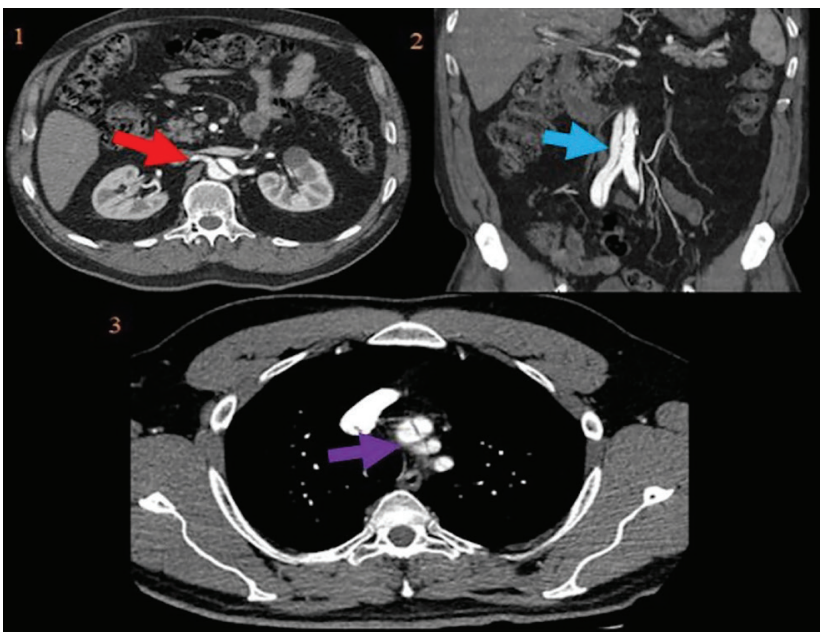

\section{Statistical Analysis}

Minitab 17 and IBM SPSS Version 21 package programs were used in statistical analyses. Median, minimum and maximum values were included in descriptive statistics. Kolmogorov Smirnov test was used to test whether the parameters were distributed normally. The relationship between parameters and the degree of relationship was tested with Pearson Correlation test. One Way Anova test (Post Hoc; Tukey, Dunnett T3) was used for the analysis of parameters according to aortic dissection types and Levene test was used to determine whether they were distributed homogeneously.

\section{Results}

$12(92 \%)$ of the 13 patients with aortic dissection were male. Mean age of the male patients was $54.00 \pm 11.49$, while the female patient was 69 years old.

According to De Bakey classification, it was found that 3 patients were Type I, 3 patients were Type II and 7 patients were Type III (Figure 3).

Mean ages of the individuals by types were found as $56.67 \pm 12.50,61.00 \pm 11.53$ and $52.00 \pm 12.26$, respectively. Mean age was found to be higher in Type II aortic dissection when compared with other dissection types (Figure 4).

The determined measurement parameters were grouped in types and median, minimum and maximum values were included in the descriptive statistics of each parameter. The highest median value of aortic arch and thoracic aorta diameter was found in Type I; the highest median value of age ascending 
Figure 3 - Distribution of patients by aortic dissection types

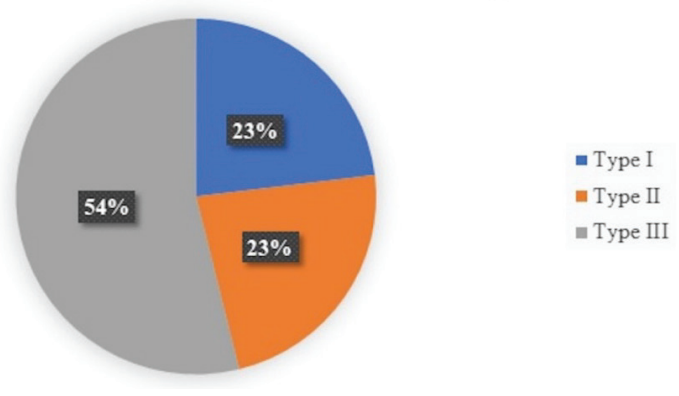

Figure 4 - Patient age distribution by aortic dissection types

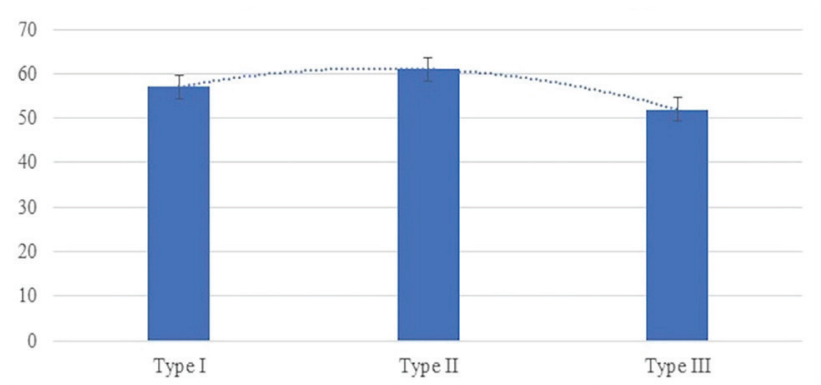

aorta diameter and cardiothoracic ratio was found in Type II and the highest median value of heart width and thoracic width was found in Type III. The highest median value of abdominal aorta was found in both Type I and Type III (Table 1).

Table 1 Table of descriptive statistics for parameters

\begin{tabular}{|c|c|c|c|c|}
\hline Parameters & Types & Median & Minimum & Maximum \\
\hline \multirow[t]{3}{*}{ Age (Year) } & Type I & 57.00 & 44.00 & 69.00 \\
\hline & Type II & 62.00 & 49.00 & 72.00 \\
\hline & Type III & 56.00 & 29.00 & 65.00 \\
\hline \multirow{3}{*}{$\begin{array}{l}\text { Ascending Aorta } \\
\text { Diameter }(\mathrm{mm})\end{array}$} & Type I & 51.00 & 40.00 & 65.00 \\
\hline & Type II & 61.00 & 45.00 & 65.00 \\
\hline & Type III & 44.00 & 30.00 & 55.00 \\
\hline \multirow{3}{*}{$\begin{array}{l}\text { Aortic Arch Diameter } \\
(\mathrm{mm})\end{array}$} & Type I & 40.00 & 31.00 & 53.00 \\
\hline & Type II & 36.00 & 34.00 & 50.00 \\
\hline & Type III & 31.00 & 25.00 & 43.00 \\
\hline \multirow{3}{*}{$\begin{array}{l}\text { Thoracic Aorta } \\
\text { Diameter (mm) }\end{array}$} & Type I & 44.00 & 29.00 & 51.00 \\
\hline & Type II & 27.00 & 24.00 & 28.00 \\
\hline & Type III & 39.00 & 33.00 & 74.00 \\
\hline \multirow{3}{*}{$\begin{array}{l}\text { Abdominal Aorta } \\
\text { Diameter }(\mathrm{mm})\end{array}$} & Type I & 28.00 & 23.00 & 50.00 \\
\hline & Type II & 24.00 & 20.00 & 25.00 \\
\hline & Type III & 28.00 & 21.00 & 58.00 \\
\hline \multirow[t]{3}{*}{ Heart Width (mm) } & Type I & 131.00 & 130.00 & 152.00 \\
\hline & Type II & 130.00 & 129.00 & 147.00 \\
\hline & Type III & 148.00 & 213.00 & 164.00 \\
\hline \multirow[t]{3}{*}{ Thoracic Width (mm) } & Type I & 258.00 & 249.00 & 291.00 \\
\hline & Type II & 240.00 & 236.00 & 269.00 \\
\hline & Type III & 269.00 & 250.00 & 287.00 \\
\hline \multirow[t]{3}{*}{ Cardiothoracic Ratio } & Type I & 0.520 & 0.500 & 0.520 \\
\hline & Type II & 0.540 & 0.530 & 0.550 \\
\hline & Type III & 0.510 & 0.420 & 0.650 \\
\hline
\end{tabular}

It was found that all parameters except abdominal aorta were normally distributed $(\mathrm{p} \leq 0.05)$. Positive and significant high correlation was found between ascending aorta diameter and age, positive and significant moderate correlation was found between aortic arch diameter and ascending aorta diameter, positive and significant moderate correlation was found between thoracic width and aorta thoracic diameter and positive and significant high correlation was found between cardiothoracic ratio and heart width $(\mathrm{p} \leq 0.05)$. No significant correlation was found between the other parameters ( $\mathrm{p} \geq 0.05$ ), (Table 2 ).

\begin{tabular}{|c|c|c|c|c|c|c|}
\hline Table 2 & Pear & n cor & tior & trix & & \\
\hline Parameters & $\underset{<}{\infty}$ & 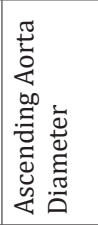 & 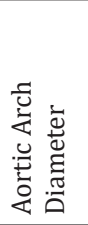 & 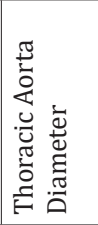 & 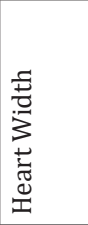 & 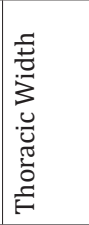 \\
\hline $\begin{array}{l}\text { Ascending Aorta } \\
\text { Diameter }\end{array}$ & $\begin{array}{l}0.762 \\
0.002\end{array}$ & & & & & \\
\hline $\begin{array}{l}\text { Aortic Arch } \\
\text { Diameter }\end{array}$ & $\begin{array}{l}0.461 \\
0.113\end{array}$ & $\begin{array}{l}0.698 \\
0.008\end{array}$ & & & & \\
\hline $\begin{array}{l}\text { Thoracic Aorta } \\
\text { Diameter }\end{array}$ & $\begin{array}{l}-0.199 \\
0.514 \\
\end{array}$ & $\begin{array}{l}-0.166 \\
0.588 \\
\end{array}$ & $\begin{array}{l}0.069 \\
0.824 \\
\end{array}$ & & & \\
\hline Heart Width & $\begin{array}{l}0.192 \\
0.530\end{array}$ & $\begin{array}{l}0.244 \\
0.421 \\
\end{array}$ & $\begin{array}{l}0.252 \\
0.405\end{array}$ & $\begin{array}{l}0.409 \\
0.165\end{array}$ & & \\
\hline Thoracic Width & $\begin{array}{l}-0.385 \\
0.194\end{array}$ & $\begin{array}{l}-0.381 \\
0.199\end{array}$ & $\begin{array}{l}0.008 \\
0.978\end{array}$ & $\begin{array}{l}0.670 \\
0.012\end{array}$ & $\begin{array}{l}0.319 \\
0.289\end{array}$ & \\
\hline $\begin{array}{l}\text { Cardiothoracic } \\
\text { Ratio }\end{array}$ & $\begin{array}{l}0.431 \\
0.141\end{array}$ & $\begin{array}{l}0.478 \\
0.098 \\
\end{array}$ & $\begin{array}{l}0.246 \\
0.417 \\
\end{array}$ & $\begin{array}{l}-0.000 \\
0.999\end{array}$ & $\begin{array}{l}0.812 \\
0.001 \\
\end{array}$ & \begin{tabular}{|l|}
-0.291 \\
0.334 \\
\end{tabular} \\
\hline
\end{tabular}

According to Levene test, it was found that all parameters except cardiothoracic ratio and thoracic aorta diameter showed a homogenous distribution. According to One Way Anova (Post Hoc; Dunnett T3) test, significant correlation was found between the Type II and Type III groups of thoracic aorta diameter $(\mathrm{p} \leq 0.05)$.

Individual's atherosclerosis and lumen status were also evaluated in our study. In terms of atherosclerosis, while 7 (54\%) of the 13 individuals were found to have mild atherosclerosis, there were no patients with severe atherosclerosis symptoms (46\%) (Figure 5).

In terms of lumen, the presence of lumen was found in 6 of 13 individuals. In 6 of the patients, main veins coming out of the aorta were coming out of the false lumen. The presence of lumen was found in two veins of 1 of these patients, in three veins of 4 patients and in four veins of 1 patient (Figure 6).

\section{Figure 5 - Distribution of patients in terms of atherosclerosis}

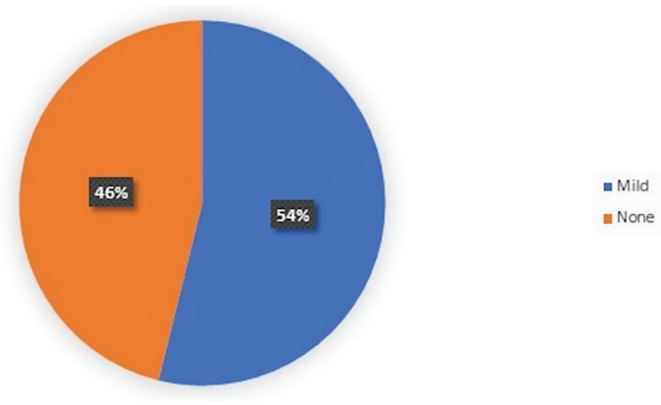

Figure 6 - Distribution of patients in terms of false lumen

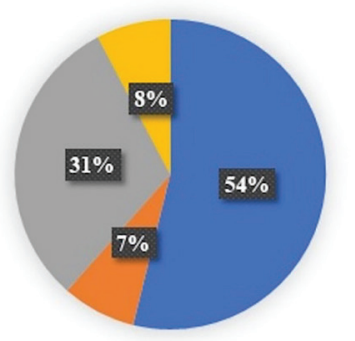

- None

- False lumen in two vessels

- False lumen in three vessels a False lumen in four vessels 


\section{Discussion}

The hypothesis of our study was based on finding out the radio-anatomic, pathological and demographic changes of aortic dissection and to show the relationships between these changes. According to De Bakey classification, the highest aortic dissection ratio was found in Type III in the study population. As a result of the analysis of aortic parameters, positive and significant moderate correlation was found between aortic arch diameter and ascending aorta diameter and between thoracic width and thoracic aorta diameter $(\mathrm{p} \leq 0.05)$. As a result of the analysis of aortic dissection types in terms of parameters, significant correlation was found between Type II and Type III groups of thoracic aorta diameter $(\mathrm{p} \leq 0.05)$. In addition, mild atherosclerosis was found in 7 of the patients, while false lumen was found in 6 .

Aortic dissection is a catastrophic disease with low incidence but high mortality [1]. The incidence of the disease is significantly increased in men who are over 40 years of age and who have a history of hypertension. The reasons for this significant age-related increase are degeneration of elastin and smooth muscle cells, which are the natural consequences of aging and the physiological $0.7-0.9 \mathrm{~mm}$ increase rate that occurs in aortic diameter every 10 years [1, 12-14]. In parallel with the literature, 12 of 13 patients were male and only 1 was female in this study, the mean age of male patients was found as $54.00 \pm 11.49$, while the age of the female patient was 69 .

Patients with aortic dissection mostly refer to the hospital with severe chest pain symptom. Since this symptom is also seen in many cardiovascular diseases, differential diagnosis is very important [3, 4]. Various radiological imaging devices (Chest X-ray, TEE, contrast CT, MRI, US) are used for differential diagnosis. These imaging technologies have their advantages and disadvantages. Although MRI has a specificity and sensitivity up to $98 \%$, it also has many disadvantages since it cannot be used in the presence of metal implants such as cardiac pacemaker and since it is not widely used. Chest X-ray is a fast, common imaging technology with low sensitivity and specificity [3]. TEE is a fast method; however, it does not allow imaging of the whole aorta $[3,14]$. On the other hand, contrast $\mathrm{CT}$ stands out as a fast method which has $98-100 \%$ sensitivity and specificity and which allows for imaging of the whole aorta. However, this method has a disadvantage of administration of contrast material $[3,14$, 15]. We conducted this retrospective study with the contrast CT images we received from hospital archive system.

In their study they conducted on 108 patients with Type A aortic dissection, Gode et al. [16] found ascending aorta diameter as $52 \pm 2.4 \mathrm{~mm}$ and they stated that $67 \%$ of the patients with dissection were male patients. In their study they conducted on 166 individuals with Type A aortic dissection, Kruger et al. [17] found the median value of ascending aorta diameter as 50 $\mathrm{mm}$ and they reported that $66 \%$ of the patients with dissection were male patients. In another study they conducted on Type A aortic dissection, Kruger et al. [12] found that $68 \%$ of 130 patients were male and the median value of the age of patients with dissection was 65 years. In a study they conducted with 225 patients with Type A aortic dissection between 2009 and 2017, Koechlin et al. [18] reported that $68 \%$ of the patients with dissection were male and the mean age of all patients was $63 \pm 12$ years. In their study, they found ascending aorta diameter as $46 \pm 8 \mathrm{~mm}$. In a study they conducted on 349 patients with aortic dissection in China population, Wu et al. [19] found the aorta diameter of 114 patients larger than $55 \mathrm{~mm}$ and reported that $82 \%$ of the patients were male. In our study, with De Bakey classification, which is a more detailed classification, we found the median values of ascending aorta diameter as $51,61,44 \mathrm{~mm}$, respectively. We found that $92 \%$ of the patients in our study were male and median values of age were $57,62,56$ years, respectively The information on ascending aorta diameter and demographic age support the literature. We believe that the reason for high percentage of male patients is due to the low population of our region and therefore low incidence of aortic dissection when compared with other studies. We think that the other reasons of this low incidence may be geographical differences, nutritional habits and stressors. The small number of cases in our study when compared with other studies in literature is a limitation of our study.

In their study they conducted on patients with aortic dissection, Barbetseas et al. [20] grouped the patients in two according to Stanford classification and found atherosclerosis pathology in $94 \%$ of Type A group and $67 \%$ of Type B group. In our study, mild atherosclerosis was found in $54 \%$ of 13 individuals with dissection. This suggests that there may be relationship between atherosclerosis and aortic dissections.

We believe that this retrospective study will contribute to early diagnosis and treatment of aortic dissections since it determines the demographic, pathological and radio-anatomical changes of aortic dissections. As a result of our study, significant correlations were found between aortic dissection and radioanatomical, pathological and demographic findings.

Disclosures: There is no conflict of interest for all authors.

\section{Acknowledgements: None.}

Funding: None.

\section{References}

1. Finkelmeier BA, Marolda D. Aortic dissection. J Cardiovasc Nurs. 2001;15(4):15-24. https://doi.org/10.1097/00005082-20010700000003

2. Deplano V, Boufi M, Gariboldi V, Loundou AD, D'Journo XB, Cautela J, et al. Mechanical characterisation of human ascending aorta dissection. J Biomech. 2019;94:138-46. https://doi.org/10.1016/j.jbiomech.2019.07.028

3. Gawinecka J, Schonrath F, von Eckardstein A. Acute aortic dissection: pathogenesis, risk factors and diagnosis. Swiss Med Wkly. 2017;147:w14489. https://doi.org/10.4414/smw.2017.14489

4. Criado FJ. Aortic dissection: a 250-year perspective. Tex Heart Inst J. 2011;38(6):694-700. PMID: 22199439

5. Tchana-Sato V, Sakalihasan N, Defraigne JO. [Aortic dissection]. Rev Med Liege. 2018;73(5-6):290-5. PMID: 29926568

6. Hughes GC. Management of acute type B aortic dissection; ADSORB trial. The Journal of thoracic and cardiovascular surgery. 2015;149(2):S158-S62. https://doi.org/10.1016/j.jtcvs.2014.08.083

7. Elsayed RS, Cohen RG, Fleischman F, Bowdish ME. Acute type A aortic dissection. Cardiology clinics. 2017;35(3):331-45. https://doi. org/10.1016/j.ccl.2017.03.004 
8. Davy H, Gates M. A case of dissecting aneurysm of the aorta. British medical journal. 1922;1(3195):471. https://doi.org/10.1136/ bmj.1.3195.471

9. LePage MA, Quint LE, Sonnad SS, Deeb GM, Williams DM. Aortic dissection: CT features that distinguish true lumen from false lumen. American Journal of Roentgenology. 2001;177(1):207-11. https://doi.org/10.2214/ajr.177.1.1770207

10. McMahon MA, Squirrell CA. Multidetector CT of aortic dissection: a pictorial review. Radiographics. 2010;30(2):445-60. https://doi. org/10.1148/rg.302095104

11. Maunoir JP. Mémoires physiologiques et pratiques sur l'anévrisme et la ligature des artères: Paschoud; 1802.

12. Kruger T, Forkavets O, Veseli K, Lausberg H, Vohringer L, Schneider W, et al. Ascending aortic elongation and the risk of dissection. Eur J Cardiothorac Surg. 2016;50(2):241-7. https://doi.org/10.1093/ejcts/ezw025

13. Schwartz SI, Durham C, Clouse WD, Patel VI, Lancaster RT, Cambria RP, et al. Predictors of late aortic intervention in patients with medically treated type B aortic dissection. J Vasc Surg. 2018;67(1):78-84. https://doi.org/10.1016/j.jvs.2017.05.128

14. Hines G, Dracea C, Katz DS. Diagnosis and management of acute type A aortic dissection. Cardiol Rev. 2011;19(5):226-32. https://doi. org/10.1097/CRD.0b013e3182203ed9

15. Heuts S, Adriaans BP, Rylski B, Mihl C, Bekkers S, Olsthoorn JR, et al. Evaluating the diagnostic accuracy of maximal aortic diameter, length and volume for prediction of aortic dissection. Heart. 2020;106(12):892-7. https://doi.org/10.1136/heartjnl-2019-316251

16. Gode S, Akinci O, Ustunisik CT, Sen O, Kadirogullari E, Aksu T, et al. The role of the angle of the ascending aortic curvature on the development of type A aortic dissection: ascending aortic angulation and dissection. Interact Cardiovasc Thorac Surg. 2019;29(4):61520. https://doi.org/10.1093/icvts/ivz144

17. Kruger T, Sandoval Boburg R, Lescan M, Oikonomou A, Schneider W, Vohringer L, et al. Aortic elongation in aortic aneurysm and dissection: the Tubingen Aortic Pathoanatomy (TAIPAN) project. Eur J Cardiothorac Surg. 2018;54(1):26-33. https://doi.org/10.1093/ ejcts/ezx503

18. Koechlin L, Macius E, Kaufmann J, Gahl B, Reuthebuch O, Eckstein F, et al. Aortic root and ascending aorta dimensions in acute aortic dissection. Perfusion. 2020;35(2):131-7. https://doi.org/10.1177/0267659119858848

19. Wu JL, Zhang L, Qiu JT, Yu CT. Morphological features of the thoracic aorta and supra-aortic branches in patients with acute Type A aortic dissection in China. Interact Cardiovasc Thorac Surg. 2018;27(4):555-60. https://doi.org/10.1093/icvts/ivy110

20. Barbetseas J, Alexopoulos N, Brili S, Aggeli C, Chrysohoou C, Frogoudaki A, et al. Atherosclerosis of the aorta in patients with acute thoracic aortic dissection. Circ J. 2008;72(11):1773-6. https://doi.org/10.1253/circj.CJ-08-0433 